\title{
Child-Led Research: Questioning Knowledge
}

\author{
Patricio Cuevas-Parra $\mathbb{D}$ and E. Kay M. Tisdall * $\mathbb{D}$ \\ Childhood \& Youth Studies Research Group, Moray House School of Education, University of Edinburgh, \\ St John's Land Holyrood Road, Edinburgh EH8 8AQ, UK; p.cuevas-parra@sms.ed.ac.uk \\ * Correspondence: k.tisdall@ed.ac.uk; Tel.: +44-131-651-6415
}

Received: 12 November 2018; Accepted: 25 January 2019; Published: 31 January 2019

check for updates

\begin{abstract}
Over the last twenty years, childhood studies has challenged the schooled and developmental models of childhood. The children's rights agenda has combined with academic childhood studies, to emphasise that children are and can be social actors and to seek ways to recognise and support their participation rights. For those who promote the participation of children and young people, there is considerable enthusiasm to involve them in all research stages-from research planning, fieldwork, and analysis to dissemination, leading to growth in what is often called 'child-led research'. This article draws upon an empirical study of 'child-led research' projects, undertaken in Bangladesh, Jordan and Lebanon, for a critical examination of the meanings and implications of 'child-led research'. In particular, this paper explores what counts as knowledge in social science research within contexts of generational difference and power.
\end{abstract}

Keywords: children; participation; child-led research; young researchers

\section{Introduction}

As more academics, research institutions and practitioners have engaged children and young people ${ }^{1}$ in research processes and recognised the value of their contributions as research respondents, there has been a significant 'turn' in childhood studies research from undertaking research on them to undertaking research with them (see Wyness 2006; Spyrou 2018; Tisdall 2018). While, in the past, adults were often treated as informants on behalf of children and young people, researchers increasingly respect that they can respond and participate on their own behalf and provide meaningful contributions to address the research questions. Research itself is no longer the sole preserve of adults; children and young people themselves are increasingly taking on different roles within research processes, from advising research studies as consultants, to peer researchers collecting and analysing data, to research collaborators. Furthermore, in recent times, academia and practice have supported an increasing engagement of children and young people as leading the research on issues that pertain to their everyday lives (e.g., Thomas 2015; Brady et al. 2018), which is frequently called 'child-led research'. Children and young people have thus moved from being the objects of research to the subjects of research and have now become the researchers themselves.

The combination of understanding children and young people as competent social actors, childhood as a social construction, and the UN Convention on the Rights of the Child's (UNCRC) ${ }^{2}$

1 This article generally uses the phrase "children and young people", following young people's typical preference to be referred to as the latter in the UK. Broadly, "children and young people" refers to children up to the age of 18, following the definition within the United Nations Convention on the Rights of the Child.

2 For example, Article 12(1) of the UNCRC states: "States Parties shall assure to the child who is capable of forming his or her own views the right to express those views freely in all matters affecting the child, the views of the child being given due weight in accordance with the age and maturity of the child". 
recognition of children and young people as right-holders has resulted in research becoming a fresh opportunity for children and young people's participation (Fleming 2011; Lundy and McEvoy 2011). Child-led research initiatives have been carried out: by academic institutions (Kellett 2005; Newell et al. 2012; Johnson et al. 2014); by NGOs as part of their international development programmes (Save the Children 2010; CESESMA 2012; World Vision 2013; Challenging Heights 2015); and by educational institutions (Thomson and Gunter 2007; Roberts and Nash 2009; Spalding 2012; Wood 2015). Other initiatives are prompted by pressure from the international community or results from the UNCRC Committee's concluding observations, which encourage States Parties and multilaterals to engage children and young people in knowledge production on how they exercise their rights in light of the implementation of the UNCRC (Miller 2007; European Union 2015). ${ }^{3}$

A growing literature demonstrates that child-led research, as a participatory approach, has proven immensely promising in influencing decision-making, by connecting children and young people's own findings to key stakeholders and decisions makers, ultimately creating change that leads to better lives for themselves and/or other children and young people (e.g., Cahill 2007; Newell et al. 2012; Houghton 2015; Tisdall 2016). In doing so, child-led research raises questions about what constitutes knowledge in social science research, within contexts of generational difference and power. This article addresses such questions, by drawing upon an empirical study of child-led research projects. The projects were led by young researchers, aged 12 to 18, and were undertaken as part of World Vision ${ }^{4}$-supported child-led research. World Vision has engaged and supported a number of child-led projects, through its various country offices across different regions. This paper discusses two child-led research projects sponsored by World Vision, in which Bangladeshi children investigated the lack of birth certificates and the possible legal implications (in Dhaka, between December 2013 and March 2014), and Syrian refugee children studied their lives as refugees in the host countries of Lebanon and Jordan (January to September 2015). A subsequent research study was then undertaken of these projects by Cuevas-Parra, with the young researchers and adults involved, to critically explore how the processes and outcomes of children and young people's participation in their own child-led research contribute, positively or negatively, to decision-making processes in the context of international development programs. In this study, the young researchers acted as research participants, not as researchers (see below for discussion). The study provides evidence for the analysis and discussion in this article.

The article begins by exploring definitions of child-led research and contestations within the literature about its credibility as social research. The article then grounds the reader in the child-led research projects and the subsequent research study. Based on these projects and research study, the article presents a critical consideration about what is essential for research to be 'child-led' and for the activities to be 'research', with three main themes arising from the empirical study: (a) how the research is carried out; (b) how adults and organisations are involved; and (c) how (and if) the research has impact. The article concludes that 'child-led' research does challenge traditional social research

3 The peer review process was suitably testing, in asking whether we could group these activities together as they were not all subject to the 'strict ethical considerations and processes that researchers comply with'. We agree that this is an important and complex issue that continues to challenge us. It is a subject mentioned but not central to the empirical study, so we cannot conclusively address. Further the comment is not so much about the ethics of child-led research, but of research undertaken by different adult-based institutions. We would reflect that it merits more investigation and discussion. For example, academic ethical regulation has considerable flaws and particularly in regard to children and children's rights (Morrow 2009; Farrell 2005; Alderson and Morrow 2011). There is much to learn from the experience of non-academic organisations, who have worked long and in-depth to consider child protection and safeguarding, social media and knowledge exchange, which has much to inform academic institutions (Tisdall et al. 2009). We do not inherently perceive academic ethical regulation as superior to other organisations' processes but rather perceive respective strengths and weaknesses. A host of debates should be held about ethical regulation, frameworks and practices, which far more fully engage in learning from children and young people's own experiences and fundamental principles of safeguarding, respect and wellbeing, which require both empirical and conceptual attention.

4 World Vision is a development, humanitarian and advocacy organisation dedicated to working with children, families and communities to overcome poverty, humanitarian disasters and injustice (World Vision 2013). 
methods and criteria as do other forms of co-production and participatory action research with adults, in terms of claims to knowledge, credibility, legitimacy and purpose.

\section{What Is Child-Led Research?}

Whilst exploring the role of children and young people in research, Kellett defines child-led research as:

Research that children design, carry out and disseminate themselves with adult support rather than adult management. (Kellett 2010, p. 195)

From Kellett's definition, child-led research has two central components: the extensive role of children and young people across the different phases of the research process and the less controlling role of adults. Thus child-led research has the potential to disrupt typical versions of generational orders and hierarchies in research, where adults are more likely to have the management power of research design, fieldwork and dissemination, with children and young people at best assisting them. Considering Kellett's two components, projects undertaken by children and young people using other labels (such as co-design, co-production, participatory action research, and social research) can be seen as very similar in process if not discourse-this shows the expansion of this sort of participatory research activity. In all these forms, the premise is that children and young people must have substantial control throughout the research stages and adults are supporting, rather than managing or undertaking, the research.

This article retains the use of 'child-led research' for two reasons. First, practically, this is the phrase used by World Vision who supported the projects considered in this article. Second, conceptually, the phrase leads us directly into the contestation of generational hierarchy and the production of knowledge. This is demonstrated by considering three leading commentators on 'child-led research', who suggest different options on how to evaluate and value such activities. ${ }^{5}$ Kellett acknowledges the contestation, with the final paragraph of her 2005 paper on 'children as active researchers':

One of the great imponderables is whether child-led research can continue to grow within existing adult research parameters or whether we need to begin to consider a new paradigm to accommodate it. What is clear is that research by children is fundamentally different from adult research about children and we cannot use the same norms of reference nor the same terms of measurement and assessment. The time to begin that deliberation process is now before we are overtaken by a wave of child-led research which we are ill-prepared for and have not properly considered how to receive it, measure it or value it. (Kellett 2005, Section 14)

Kellett suggests that there is a fundamental difference between adult-led and child-led research and that they should be assessed differently. She implies that they can have equal merit, if such assessments were developed particularly for child-led research. Hammersley (2017), writing over ten years later, comes to a different conclusion. He also sees children's activities as fundamentally different from adult research but child-led activities are not social research:

Indeed, I question whether participatory inquiry, especially when it is child-led, is a research method at all ... In methodological terms, I think it is important to recognise that social research is a specialised activity that demands knowledge and skills that a very small proportion of adults-and hardly any children - have, and ones that cannot by acquired quickly. ... Research involves responsibilities, both as regards seeking to ensure the validity of the findings and respecting ethical considerations-and researchers

5 Other resources include Petrie et al. (2006), Connolly (2008), Holland et al. (2008), Spyrou (2011), Tisdall (2012), Laura and Swadener (2014), Bradbury-Jones and Taylor (2015), Thomas (2015), Van Blerk et al. (2016). 
must be in control of research decisions if they are to live up to those responsibilities ... (Hammersley 2017, p. 122)

Hammersley thus questions the knowledge and skills of children and young people as social researchers and their ability to take on the responsibilities required of research, both analytical and ethical.

Hammersley recognises, in this critique, that much depends on how social research is defined. This is picked up by Spyrou in his 2018 book:

Indeed, if the goal of research is not exhausted by the need for validity, reliability, rigour and so on, but also encompasses the need for participation, political engagement and social change, then one can envision a place for research produced by children in the larger world of research. (Spyrou 2018, p. 166)

Spyrou's answer, then, is to widen the definition of social research to include children and young people's activities. He goes on to show how the involvement of children and young people, and their own perspectives, can test and widen ideas and assumptions of adult researchers-potentially to make everyone's research more rigorous. Thus, between Kellett, Hammersley and Spyrou we have different options to consider child-led research: for Kellett, child-led research is research but needs to be assessed differently than adult-led research; to Hammersley, it is a participative inquiry but not social research; and, for Spyrou, child-led research could be research if the goals of research were expanded. This article will return to these options in the conclusion, to consider in light of the study's findings.

More generally in social research methods textbooks and literature, there is contestation about what social research does and should consist of. In his seminal methods textbook on social research, Blaikie (2009) describes social research as one of the main contributors to scientific knowledge generation, which is achieved through acquiring specific types of information using queries, which, in conjunction with the research purpose, identify and produce a particular form of knowledge. According to May (2011a), social research is not just a data-gathering process, but is determined by the relationship between empirical data and social theory:

We aim, with our training and experiences of doing research in mind, together with the perspectives that guide our thinking, to understand the social world. This requires the development, application, testing and even falsification of social theory. (May 2011a, p. 27)

Following this view, social theory is essential to social research, as it interacts with practice to lead to particular understandings of the social world. Such theorisation, however, is arguably not a neutral interpretation of empirical data but embedded in all the practices of social research-from the questions to be asked, to the research design, to the analysis and outcomes-with social and political implications. Standpoint feminism, for example, has played a leading role in recognising the power of producing knowledge. May writes about its contribution:

If a certain type of knowledge predominates in a society, this is not necessarily because it is scientific, but due to the power that certain groups have to define what is right or wrong, or true or false. (May 2011a, p. 38)

To date, adults and particular adults (funders, academics, peer reviewers, etc.) have largely defined what is scientific knowledge and what is social research (Hordijk and Baud 2006; Cahill 2007; Schäfer and Yarwood 2008). Child-led research is a potential challenge to this, particularly for the potential for children and young people to be producers of knowledge, which is 'scientific' and can help explain and understand the social world. We will explore this potential below, through examples of child-led research.

\section{Examples of Child-Led Research: The Empirical Study's Methodology}

This article draws upon an empirical study of child-led research projects undertaken in Bangladesh, Jordan and Lebanon. The term 'young researchers' is used here and subsequently 
in discussing the projects, to refer to the children and young people who undertook the child-led research, because it is the term they explicitly asked to be used.

World Vision has developed a series of child-led projects, through its various local offices world-wide. Two of these became part of the empirical study. The first one, Bekaa and Irbid, involved Syrian refugee children who conducted their own child-led research on issues relevant to their lives as Syrian refugees in the host countries of Lebanon and Jordan. This was carried out from December 2013 to March 2014 as part of the activities to mark the third anniversary of the war in Syria and provided an opportunity for them to express their concerns, needs and aspirations. The second project, Dhaka, was conducted from January to September 2015. Members of a Children's Parliament in Bangladesh chose to investigate that lack of birth certificates and the possible effects of not having this legal registration. The young researchers from Dhaka, Bekaa and Irbid led the research and developed research questionnaires, collected and analysed data and prioritised their findings in order to provide a set of recommendations on how to make changes in their lives. The child-led research projects were framed by World Vision's guidelines in terms of child protection and safeguarding, which include informed consent process for the young researchers and their research participants, processes to ensure the safety and wellbeing of children and young people, and protocols for dissemination

The subsequent empirical research study critically explored how the processes and outcomes of children and young people's participation in their own child-led research contribute, positively or negatively, to decision-making processes in the context of international development programs. Qualitative research was undertaken with 34 young people, aged 12 to 18 , who had acted as young researchers within the above projects. Of these 34 young researchers, 20 were girls and 14 were boys. All children and young people who had been involved as young researchers were invited to be part of the study; out of the 65 young people, 31 were not contactable and all contactable young researchers agreed to participate. Fourteen adult professionals were interviewed, selected because they had acted as facilitators, worked in the design of these projects or dissemination of the child-led research findings. These constituted all the professionals who took on these key project roles. The methods for data collection included focus groups, semi-structured interviews and observation, which together facilitated the exploration of the personal knowledge, experiences and attitudes of the research participants (Ritchie 2009). Focus groups, for example, used a variety of methods with the young researchers, including a 'learning from our experiences' tool, a 'road map' tool and a 'collaging our ideas' tool. Young people were involved in 2 focus groups, initially, followed by subsequent discussion groups to discuss findings. The research was undertaken with the young researchers in their own language, with an interpreter translating between the young researchers and the adult researcher, Cuevas-Parra. The sessions with young people were all transcribed first in the original languages and then translated into English. Queries about certain words that did not translate easily became sources of reflection and exploration, in subsequent discussions with the young researchers. Interviews with adults were undertaken in English. Analysis was primarily thematic, seeking to answer the research questions deductively as well as recognising emerging issues from the data (Guest et al. 2012). Attention was given to differences across study participants, such as gender and age; for the findings discussed in this article, no significant differences were identified although there were certain differences by gender on other issues (see Cuevas-Parra 2018). Young people were not themselves researchers in this study because they felt their current commitments and responsibilities (e.g., school and household chores) were too considerable at the time. Further, some young researchers expressed 'research fatigue' due to having finished their project recently and were not ready to join a fully new project. The young researchers provided helpful advice on the research design and methods and were involved in validating the findings through subsequent discussion groups with Cuevas-Parra.

Ethics were given considerable attention throughout the study. Detailed protocols were considered initially and throughout the research, covering such issues as informed consent, ensuring confidentiality, acknowledge the cultures of the research sites, and refraining from presenting information that may potentially harm participants (Marshall and Rossman 2006) (for further 
information, see Cuevas-Parra 2018). All participants gave their informed consent for inclusion before they participated in the study. To ensure the participants' privacy, data were anonymised and all identifiers, such as family names and contact details, were removed from the notes (Preston-Shoot et al. 2008). Pseudonyms are used in reporting on the study, including within this article. As this research was conducted at distinct sites characterised by their own traditions and heritages, the ethical considerations were tailored to reflect the cultures of the sites (Skelton 2008), including respecting local traditions, customs and local knowledge. The study was conducted in accordance with the Declaration of Helsinki, as required and approved by the Research and Ethics Committee of the School of Social and Political Science, University of Edinburgh.

Three themes arose from the analysis, which are pertinent to the agenda of this article:

(a) How the research is carried out: the centrality and importance of the young researchers' experiences

(b) How adults are involved: adult and organisational control, facilitation and support

(c) How the research has impact: who decides on knowledge exchange

These are discussed below.

\section{How the Research Is Carried Out: The Centrality and Importance of Young Researchers' Experiences}

The experiences of the young researchers were considered essential to their projects. According to the study participants, what made this type of research different from other types of research was its ability to broadly and deeply learn of and from children and young people's experiences.

The first finding here is well-rehearsed within childhood studies (e.g., Cahill 2007; Schäfer and Yarwood 2008; Ansell et al. 2012; Törrönen and Vornanen 2014)—but very important to, and consistent across, study participants. The young researchers were perceived as being particularly good at researching other children and young people. They were described as especially good at recruiting children and young people, by having peer and community networks not accessible to adult researchers. They were described as having particular skills in communicating with other children and young people, in 'ordinary' or 'easy to understand' ways. With these abilities, they were then able to gather information that otherwise would not have been elicited. This view is exemplified by Amal, a young researcher from Lebanon:

We discovered issues that were covered or hidden, and we brought them into the light and exposed them to the public. We explained in detail the things that affect children. (Amal, aged 16, Lebanon)

Thus, young researchers would both improve the content of the research-learning of issues that otherwise would not have been known—and the quality of the research-the young researchers would learn in detail about how children are affected. Common across the study participants was the view that, assisted by improved recruitment and communication with peers as compared to adult researchers, the young researchers would gather better data and thus generate better knowledge.

The second finding brings in the young researchers' experiences in another way, to their projects. The young researchers saw their own experiences as a crucial resource for the generation of knowledge, in their projects. Faria's view is typical of other young researchers, when she said: "We know more and better about what happened to us. So, we can research our own issues" (Aged 13, Bangladesh). Thus, young researchers are better able to identify the research issues to be researched than adults, from the start: taking on a key role in research initiation and design, of problem identification. The young researchers also perceived their experiences as key to their data analysis and production of findings. A quotation from one young researcher exemplifies this:

When we write about ourselves this becomes like an eye witness, because it happens to us.

(Malik, aged 14, Jordan) 
In the analysis phase, the young researchers reported exploring the issues from their personal perspectives, using their individual experiences to understand the topics under examination and presenting new insights. The young researchers thus included their own personal experiences as part of the research data. Further, these experiences were used as a resource for analysis. The young researchers perceived such use of their personal experiences as a considerable strength and central to what makes child-led research.

From a social research perspective, how can we consider this approach? Following Hammersley, we could conclude that child-led research is not meeting the rigorous standards of social research-the research design and even more problematically the analysis is unduly subjective, too reliant on the particular researchers involved (for a review of such critiques, see May 2011a; Ansell et al. 2012). The young people could be seen as lacking the knowledge and skills to recognise their subjectivity and consider it accordingly. The young people thus risk not taking on the responsibilities of social researchers, in generating findings. Yet, several young researchers reflected on the data-gathering and analysis stage, which suggests that attention was given to this risk. For example, Kamira commented on how his own experiences were similar and different from those he researched:

Before, I thought that my problems were only my problems but, when I interviewed other children, I learned that we shared similar problems and others suffered more than me and they had another kind of problems. (Kamira, aged 16, Jordan)

Kamira was thus open and able to perceive both the similarities with and differences from his own experiences, in undertaking and reporting on the research. This is a similar finding to other child-led research, where young researchers are often highly sensitive to claims that they are 'unrepresentative' and prioritise research methods that reach out to a range of other children and young people to ensure they have a breadth of perspectives (Ansell et al. 2012; Tisdall 2015; McMellon and Mitchell 2017). Young researchers can be very aware of the potential criticisms of their own bias.

Considering the young researchers' reflections from the projects, at least two other possibilities arise to understand their use of experiences. The first is autoethnography, which is increasingly discussed in academic literature. An early and seminal definition of autoethnography is given by Reed-Danahay: it is "a form of self-narrative that places the self within a social context" (Reed-Danahay 1997, p. 9). May (2011b) puts this more simply, describing autoethnography as a research method using "the researcher's own experiences as ethnographic data" (p. 2); Butz and Besio (2009) defines autoethnography with more complexity as a form of non-conventional writing that "radically foregrounds the emotions and experiences of the researcher as a way to acknowledge the inevitably subjective nature of knowledge, and in order to use subjectivity deliberately as an epistemological resource" (p. 1662). This definition goes to the heart of the controversies over autoethnography, as a social research method, because it questions what constitutes social science knowledge. While some autoethnographers respond to critiques by favouring narrative truth to the subjective experience, other autoethnographers argue for focusing on personal experiences for "their ability to speak about collective social processes beyond the individual experiences" (May 2011b, p. 3). It is this latter argument that chimes with the young researchers' views about integrating their experiences, as exemplified above. They describe their own experiences as resources for the research, both in terms of focus and analysis. While their research written outputs do not follow the practices of autoethnography in terms of narrative presentation and other alternatives (see Butz and Besio 2009 for typology), nor do they position their research as autoethnography, there are commonalities in terms of the valuing and place of personal experiences to illuminate the social and the collective.

Standpoint research also privileges biography and experience. Developed by a number of disciplines, such as feminism and disability studies (e.g., Oliver 1997; Connolly 2008; Cornwall and Fujita 2012; Mackenzie et al. 2012; Rayaprol 2016), biography and experience are central to producing valuable research. Because women and disabled people have too often been excluded from or under-valued by the public realm generally and social research in particular, their experiences and biographies can provide unique opportunities for undertaking research (May 2011a). These experiences 
are a starting point for research, but not the end, as the research then situates such experiences in a wider context and knowledge becomes a social activity (Harding 1987; May 2011a). Spyrou (2018) explores the potential of child-led research to be considered standpoint research, on the basis of shared experiences of childhood-in part shared because of generational power structures that render children as a minority group. The young researchers' own reflections are akin to such discussions, as demonstrated above. They describe themselves as having a shared standpoint with other children in similar positions (not all children, but young refugees in Jordan or in Lebanon, or young people or children in their local communities in Bangladesh) and their research as key to making their and other children's knowledge known and valued.

Both autoethnography and standpoint theory are research approaches that fundamentally question the generation and valuing of knowledge in social research. They challenge and illuminate the power relations underlying social research. But standpoint theory, and even more so autoethnography, are not accepted by all social researchers and continue to be critiqued for their subjectivity. They do provide resources to consider how young researchers use their own experiences, which parallel the young researchers' own explanations, and highlight the contestations of knowledge production in child-led research.

\section{How Adults Are Involved: Adult and Organisational Control, Facilitation and/or Support}

When the study asked about the definition of child-led research, both the young researchers and adult participants commented extensively on the role of adults and organisations. The claim was for child-led research, not child-only research. A clear commonality across all the projects was that adults were involved, and that all study participants thought adults and organisational support were essential for these forms of child-led research to exist and flourish.

Thus, this raises the question, if adults were involved, then how was it child-led? Again, both the young researchers and adult participants were consistently clear on the respective relationships. Adults were to facilitate, to provide logistical support, to provide advice but the young researchers decided how to carry out the research, the topics to investigate within that, the analysis and the findings. As exemplified by Abdulla, the young researchers typically commented on this emphatically: "We decided to do the research, we prepared the questions. We interviewed other children and wrote the report. No adults did this job for us" (Aged 18, Jordan). As with Abdulla, the young researchers were consistently confident that they were decision makers across the different phases of their research processes. The young researchers claimed ownership of their child-led research projects with the understanding that the adults provided support. The extent and consistency of this clear and confident articulation implicitly addresses the argument that these projects were not child-led. Sometimes this argument was made explicitly by adults outside the projects, such as the German Government Minister's surprise and appreciation, on reading the report and meeting with the young researchers from Jordan and Lebanon, that this was their own work. The young researchers' and adult participants' own definitions of child-led research were in counter-point to critiques that they may not be truly the children's own work.

The adult and organisational involvement did create issues of power and control. One example was who instigated the research, both in terms of content and process. In the child-led research by Syrian refugees, World Vision brought together the young researchers in the first place and an agenda was already set-the experiences of young Syrian refugees in their host countries. Within this was considerable scope for the young researchers to decide in the research project but the agenda was not fully open. In Bangladesh, the young researchers decided the research topic. The Bangladeshi project was part of longer-term community work and thus the children and young people's own agenda could influence even earlier on in the research process than in Jordan and Lebanon. Longer-term relations with adults and supporting organisations provided more opportunity for children and young people's control from the start of research design. 
The adult facilitator was an essential pivot to the power balance between adults and children. The study shows that when the adult facilitators embraced the concept of children and young people as competent researchers and took a facilitating but not controlling role, then children and young people felt they could indeed carry out the research (see Le Borgne and Tisdall 2018 for similar findings). As vitally important to the young researchers were their relationships with the adult facilitators, and the facilitators' personal and professional style. If the adult facilitator were friendly, interested in the young people as individuals, fun and supportive, then the adult worker was described as a considerable support both to the young researchers individually but also for the research's success. Tahirah, a 13-year-old Syrian young researcher, shared a commonly expressed view about their adult facilitator: "He had a good heart and was very kind". Dalia, aged 14, built on this reflection and added: "He was always smiling and helping us. He supported and gave very positive comments even though we knew that the things were not perfect. He was always cheering us up". Child-led research undertaken in other countries point to the importance of fun and support not only as central to ensuring that the young researchers continue with the research but as an ethical requirement (e.g., Houghton 2015). Adult study participants reflected that such qualities are not normally part of job recruitment procedures for these kinds of post: research degrees or skills would be far more likely to be part of a job specification. These affective, emotional elements of trust and relationships are perhaps under-recognised and under-valued by adults and organisations but are very important to young researchers.

In short, the young researchers and adult participants in the study were emphatic that the projects were child-led research. Adults had a distinct role, to provide support, facilitation and sometimes knowledge, but not to control. The reassertion of adult-child hierarchies and the generational order hovered, however, with adult practitioners or organisations able to take back their control should they not recognise the young researchers as competent. The emotive elements of trust and relationships were important to the young researchers' continued commitment to and success of the project; these are not always recognised by adults and organisations as ethical and central principles to research and its facilitation.

\section{How the Research Has Impact: Who Decides on Knowledge Exchange?}

What happens to research findings and their impact has become of increasing interest to social research, both theoretical and practically (Lomas 2000; Nutley et al. 2009; Morton and Fleming 2013; Morton 2015). Commonly known as 'knowledge exchange' in the United Kingdom, the phrasing highlights the role of knowledge within this aspect of the research process. Social research, then, needs to consider not only knowledge generation but the exchange of knowledge, its dissemination and its impacts on policy and practice.

The power and control of certain adults in knowledge exchange became particularly evident in the child-led research projects. For the child-led research by Syrian refugees, adults and organisations took the lead in the knowledge exchange phase, to ensure the research had an impact beyond the community boundaries where the young researchers lived. Further, the supporting local officers were concerned that the young researchers were 'vulnerable', as they were not always welcomed locally due to their refugee status. In order to prevent any child protection incidents, the young researchers were not substantially involved in public activities, such as the report launch and meetings with key stakeholders to publicise the findings. The young researchers were not part of this decision but they broadly accepted it as they agreed with the risks outlined by the adults. Adult participants in the study reflected that they could have involved the young researchers more in the decision-making, particularly in developing the knowledge exchange strategy. The adults' focus on the young researchers' vulnerability led to excluding them from such potential decisions.

This study found that the young researchers were not aware of the full range of dissemination activities, and indeed where the research had been picked up and potentially influenced 
decisions—-some quite high level in the United Nations. Hanadi, a Syrian refugee young researcher, expressed his feelings on this:

When we were writing the report, I did not expect too many things but [I hoped] at least to do something that can touch people's hearts, their feelings. I wrote a quote and felt this quote touched me, and I was sure that it could touch other people. I expected that this small paragraph would touch people, but I do not believe it made a change in our lives ... (Hanadi, aged 16, Lebanon)

In this reflection, Hanadi expressed frustration because she thought that her contribution to the research, especially the appealing quote she wrote by herself, did not "touch people's hearts" as she expected. However, Hanadi did not know that this quote was used several times in international forums and conferences and reproduced in blogs and newspapers. This situation reflects one of the criticisms of children and young people's participation, which is the lack of feedback from organisations and adults who engage in dialogue with them (e.g., Alderson 2001; Davis 2009; Skelton 2008; Tisdall 2014; Sharpe 2015).

This contrasts with the young researchers who were highly involved in knowledge exchange in Bangladesh. For instance, in Bangladesh, the young researchers developed their own knowledge exchange strategy to identify and reach relevant decision makers, including a media action plan targeting editors and journalists to promote their findings. One young researcher explained their plan and its progress:

We are halfway; we have done many things to make a change with our research, but we need to do more. I thought that our work finished with the report writing, but then we wanted to do more and more. People need to know about our findings and the government needs to change many things. (Abhoy, aged 14, Bangladesh)

Abhoy's explanation places himself and his associates as the key actors in this plan and expresses both a sense of achievement (we have done many things) but that more was needed and planned. The young researchers were able to take such knowledge exchange activities forward because both adult facilitators and the organisation provided the community contacts so that the young researchers could tap into decision makers, often local ones, and have clear commitments and plans for change. The prior and background work of the adults and supporting organisation assisted the young researchers to take forward their knowledge exchange strategy, but the young researchers felt ownership of the strategy and it was for them to carry out.

The differences between the projects highlight how generational order can reassert itself in child-led research through knowledge exchange. The ability to disseminate, to influence, to connect with local, national and international stakeholders is an aspect of power over and of knowledge. It was a particular tenuous one for the young researchers to claim and promulgate their own and their project's knowledge and they were highly reliant on the supporting adults and organisations. In Bangladesh, adult and organisational networks became resources for the young researchers to plan and carry out their knowledge exchange strategy. In Jordan and Lebanon, concerns about the young researchers' vulnerability and the organisation's focus on international impact resulted in the young researchers being less involved in deciding on the knowledge exchange strategy and less aware of what impacts their research had made.

\section{Conclusions}

Child-led research is challenging 'traditional' social research, by questioning what constitutes knowledge, within contexts of generational difference and power. It does so in at least three ways: how researchers' personal experiences generate knowledge, the roles of supporting adults and organisations for young researchers, and questioning adult control of knowledge exchange.

All participants saw the young people's experiences as essential to their ability to be, and the benefits of being, young researchers. Such experiences were considered as creating better knowledge, 
because of improved recruitment, communication style, content and analysis. This questions the presumed expertise of adult researchers to carry out these tasks, requiring particular skills gained by training and research experience: it upsets the presumption that these are required to produce better knowledge.

Another consistent finding across the participants and projects was that child-led research did require adult and organisational involvement-but that adults and organisations needed to facilitate and not manage. This would retain the integrity of the child-led research process, so that the knowledge production was indeed theirs. As reviewed above, Kellett and others define child-led research as young researchers having considerable control over all aspects of research, from design to fieldwork to analysis. The study discussed here suggests that this generation of knowledge is central to the definition of child-led research - but also the use of this knowledge to influence policy and practice. All study participants were very explicit that child-led research intended to have an impact, in particular to improve their and other children's experiences. The study took an iterative approach with participants, to test out and agree a definition of child-led research. The resulting definition is:

Children and young people lead their own research process (designing the questionnaires, collecting information, analysing the results, and writing and disseminating their report). In this process, children and young people can be assisted by an adult facilitator, but this adult only helps the young researchers and doesn't manage or direct the research project. Child-led research is always connected to children's and young people's interests and their motivation to make a difference. (World Vision 2015, p. 9)

This emphasis on impact is challenging. While it precludes young researchers investigating topics that are not central to children and young people's interests, it draws attention to the power over knowledge exchange: that we need to consider as much how the knowledge is used as how it is generated in child-led research.

Research, with its exchange between social theory and empirical 'evidence', is fundamentally about the generation of knowledge. It makes particular claims to credibility and legitimacy, by being more than opinion, to being knowledge that has value and thus has power. The study's adult participants frequently used the terms credibility and legitimacy to value the child-led research, particularly in relation to the young researchers' control over the research process and the quality of the process itself. The child-led research was positioned as a participatory activity-but a particular one that also counted as research.

Kellett, Hammersley and Spyrou offer different resolutions for child-led research in relation to (valued) social research, as reviewed above. Kellett suggests that alternative assessments can be used to measure and assess child-led research. This study points to some criteria that are not always contained in adult-led research: ethical principles to ensure the wellbeing and enjoyment of both research participants and researchers; the extent of researcher control and investment; the role of researchers' personal experiences. But we challenge whether the criteria need to be so different between child- and adult-led research but rather between different types of social research.

Hammersley's view is testing, in whether children and young people (or indeed most adults) can have the necessary skills and knowledge to carry out social research. Given the range of skills that children and young people have shown in this regard in different research contexts, ${ }^{6}$ it would seem that this is very possible but not necessarily always present in child-led research. His discussion is even more testing when considering the responsibilities of undertaking research, ethically and analytically. This study shows that the young researchers took such issues seriously and the adult facilitators sought to support them in doing so. One answer to Hammersley could be the distributed, collective nature of the research enterprise of these projects. Unlike the 'lone academic' researcher

6 For example, the Youth Research Academy training in mixed methods, through the McCreary Centre Society (https://www.mcs.bc.ca/) and the young peer researchers in Growing up on the Street (https://arcg.is/0L8PSm). 
and an individualised responsibility, the young researchers worked as a group, with adult workers and organisational scaffolding, to undertake this research. In a sense, this combination had collective responsibilities for ethics and analysis rather than the more individualistic responsibility familiar to academic researchers.

The study's conclusions are closer to Spyrou's suggestion about how inclusive the definition of social research is and whether it can include aspects such as participation and social justice. We take his suggestion further, to consider the potential similarities with standpoint research that he addresses as well as the claims and contestations of autoethnography. As these alternative research approaches illuminate, what is at stake is who controls the generation of power over and use of knowledge. This is not a child-adult only question, but one that is evident in other hierarchies and orders, as is being questioned in research labelled as co-production or co-design and participation action research (e.g., see Beebeejaun et al. 2013; Durose et al. 2011; Campbell and Vanderhoven 2016). The question then becomes not of child-led research being legitimate research but of social research's claims to knowledge, legitimacy and credibility.

Author Contributions: Relevant contributions are: Conceptualization P.C.-P. and E.K.M.T.; Methodology P.C.-P. and E.K.M.T.; Formal Analysis P.C.-P.; Writing-Original Draft Preparation P.C.-P. and E.K.M.T.; Writing-Review and Editing P.C.-P. and E.K.M.T.; Supervision E.K.M.T.

Funding: The empirical study referred to in the article received no external funding.

Acknowledgments: We would like to thank the generous contributions of children and young people and adults who were part of the empirical study. We wish to acknowledge the contribution to the empirical study, of Ian Fyfe at the University of Edinburgh, who co-supervised the Ph.D. study. Kay Tisdall acknowledges a range of collaborative projects funded by the Big Lottery Fund, the British Academy, Economic and Social Research Council (R451265206, RES-189-25-0174, RES-451-26-0685) and Knowledge Exchange funds from the University of Edinburgh and the ESRC Impact Acceleration Account, the European Research Council, the Foundation of Canadian Studies, the Leverhulme Trust, the Royal Society of Edinburgh and the Social Sciences and Humanities Research Council of Canada. We appreciate the detailed comments from anonymous reviewers of the draft article.

Conflicts of Interest: The authors declare no conflict of interest. For clarification, Patricio Cuevas-Parra is employed by World Vision International. The empirical study used within this article was undertaken by Patricio Cuevas-Parra, as part of his Ph.D. at the University of Edinburgh. It was not directly funded nor commissioned by World Vision.

\section{References}

Alderson, Priscilla. 2001. Research by children. International Journal of Social Research Methodology 4: 139-53. [CrossRef]

Alderson, Priscilla, and Virginia Morrow. 2011. The Ethics of Research with Children and Young People: A Practical Handbook. London: Sage.

Ansell, Nicola, Elsbeth Robson, Flora Hajdu, and Lorraine van Blerk. 2012. Learning from young people about their lives: Using participatory methods to research the impacts of AIDS in southern Africa. Children's Geographies 10: 169-86. [CrossRef]

Beebeejaun, Yasminah, Catherine Durose, James Rees, Joanna Richardson, and Liz Richardson. 2013. 'Beyond text': Exploring ethos and method in co-producing research with communities. Community Development Journal 49: 37-53. [CrossRef]

Blaikie, Norman. 2009. Designing Social Research. Cambridge: Polity.

Bradbury-Jones, Caroline, and Julie Taylor. 2015. Engaging with children as co-researchers: Challenges, counter-challenges and solutions. International Journal of Social Research Methodology 18: 161-73. [CrossRef]

Brady, Louca-Mai, Lorna Templeton, Paul Toner, Judith Watson, David Evans, Barry Percy-Smith, and Alex Copello. 2018. Involving young people in drug and alcohol research. Drugs and Alcohol Today 18: 28-38. [CrossRef]

Butz, David, and Kathryn Besio. 2009. Autoethnography. Geography Compass 3: 1660-764. [CrossRef]

Cahill, Caitlin. 2007. The personal is political: Developing new subjectivities in a participatory action research process. Gender, Place, and Culture 14: 267-92. [CrossRef]

Campbell, Heather, and Dave Vanderhoven. 2016. Knowledge That Matters. Available online: https: / / www.n8research.org.uk/knowledge-that-matters-realising-the-potential-of-co-productionlaunch-of-final-report/ (accessed on 8 November 2018). 
CESESMA. 2012. Learn to Live without Violence: Transformative Research by Children and Young People. Edited by Harry Shier. Preston: University of Central Lancashire and CESESMA, Available online: http://www. harryshier.net/docs/CESESMA-Learn_to_live_without_violence.pdf (accessed on 10 July 2015).

Challenging Heights. 2015. Child-Led Research Project 201 "Teenage Pregnancy". Available online: http:/ / challengingheights.org/wp-content/uploads/2014/11/Child-led-research-teenage-pregnancyCH-FINAL-report-24-Oct-2013.doc (accessed on 22 September 2016).

Connolly, Paul. 2008. Race, gender and critical reflexivity in research with young children. In Research with Children, Perspectives and Practices. Edited by Pia Monrad Christensen and Allison James. London: Routledge.

Cornwall, Andrea, and Mamoru Fujita. 2012. Ventriloquising 'the Poor'? Of voices, choices and the politics of 'participatory' knowledge production. Third World Quarterly 33: 1751-65. [CrossRef]

Cuevas-Parra, Patricio. 2018. Exploring Child-Led Research: Case Studies from Bangladesh, Lebanon and Jordan. Ph.D. thesis, University of Edinburgh, Edinburgh, UK. Available online: https:/ / www.era.lib.ed.ac.uk/ handle/1842/33057 (accessed on 9 January 2019).

Davis, John M. 2009. Involving children. In Research with Children and Young People: Research Design, Methods and Analysis. Edited by E. Kay M. Tisdall, John M. Davis and Michael Gallagher. London: SAGE.

Durose, Catherine, Yasminah Beebeejaun, James Rees, Jo Richardson, and Liz Richardson. 2011. Toward Co-Production in Research with Communities. Available online: http://www.ahrc.ac.uk/documents/ project-reports-and-reviews / connected-communities / towards-co-production-in-research-withcommunities / (accessed on 8 January 2019).

European Union. 2015. Evaluation of Legislation, Policy and Practice on Child Participation in the European Union (EU): Research Summary. Available online: https:/ / publications.europa.eu/en/publication-detail/- / publication/f425176f-cc2c-46bd-8a3a-65d958fff780/language-en (accessed on 2 April 2017).

Farrell, Ann. 2005. Ethical Research with Children. Maidenhead: Open University Press.

Fleming, Jennie. 2011. Young people's involvement in research: Still a long way to go? Qualitative Social Work 10: 207-23. [CrossRef]

Guest, Greg, Kathleen M. MacQueen, and Emily E. Namey. 2012. Applied Thematic Analysis. Thousand Oaks: SAGE. Hammersley, Martyn. 2017. Childhood Studies: A sustainable paradigm? Childhood 24: 113-27. [CrossRef]

Harding, Sandra. 1987. Feminism and Methodology: Social Science Issues. Bloomington: Indiana University Press.

Holland, Sally, Emma Renold, Nicola Ross, and Alexandra Hillman. 2008. Rights, 'Right on' or the Right Thing to Do? A Critical Exploration of Young People's Engagement in Participative Social Work Research. Working Paper. Southampton: ERSC National Centre for Research Methods, Available online: http:/ / eprints.ncrm.ac.uk/ 460/1/0708\%2520critical\%2520exploration.pdf (accessed on 8 January 2019).

Hordijk, Michaela, and Isa Baud. 2006. The role of research and knowledge generation in collective action and urban governance: How can researchers act as catalysts? Habitat International 30: 668-89. [CrossRef]

Houghton, Claire. 2015. Young People's Perspectives on Participatory Ethics: Agency, Power and Impact in Domestic Abuse Research and Policy-Making. Child Abuse Review 24: 235-48. [CrossRef]

Johnson, Vicky, Roger Hart, and Jennifer Colwell. 2014. Steps to Engaging Young Children in Research. Available online: https:/ / bernardvanleer.org/publications-reports/steps-engaging-young-children-research-volume1-guide/ (accessed on 22 December 2015).

Kellett, Mary. 2005. Children as Active Researchers: A New Research Paradigm for the 21st Century? Swindon: ESRC. Available online: http:/ / oro.open.ac.uk/7539/1/ (accessed on 10 November 2014).

Kellett, Mary. 2010. Small Shoes, Big Steps! Empowering Children as Active Researchers. American Journal of Community Psychology 46: 195-203. [CrossRef] [PubMed]

Le Borgne, Carine, and E. Kay M. Tisdall. 2018. Children's Participation: Questioning Competence and Competencies? Social Inclusion 5: 122-30. [CrossRef]

Lomas, Jonathan. 2000. Using 'Linkage and Exchange' to Move Research into Policy at a Canadian Foundation. Health Affairs 19: 236-40. [CrossRef] [PubMed]

Laura, Lundy, and Beth Blue Swadener. 2014. Participatory Rights-Based Research: Learning from Young Children's Perspectives in Research That Affects Their Lives. In Handbook of Research Methods in Early Childhood Education. Edited by Olivia N. Saracho and Bernard Spodek. Charlotte: Information Age Publishing, vol. 2.

Lundy, Laura, and Lesley McEvoy. 2011. Children's rights and research processes: Assisting children to (in)formed views. Childhood 19: 129-44. [CrossRef] 
Mackenzie, John, Poh-Ling Tan, Suzanne Hoverman, and Claudia Baldwin. 2012. The value and limitations of Participatory Action Research methodology. Journal of Hydrology 474: 11-21. [CrossRef]

Marshall, Catherine, and Gretchen B. Rossman. 2006. Designing Qualitative Research. Thousand Oaks: Sage.

May, Tim. 2011a. Social Research, 4th ed. Berkshire: Open University/McGraw Hill.

May, Vanessa. 2011b. Autoethnography. In Encyclopedia of Consumer Culture. Thousand Oaks: Sage, p. 78.

McMellon, Christina, and Mary Mitchell. 2017. Participatory Action Research with Young People. In Building Research Design in Education. Edited by Lorna Hamilton and John Ravenscroft. London: Bloomsbury Publishing.

Miller, Jennifer. 2007. Children as Change Agents: Guidelines for Child Participation in Periodic Reporting on the Convention on the Rights of the Child. Mississauga: World Vision Canada.

Morrow, Virgina. 2009. The Ethics of Social Research with Children and Families in Young Lives: Practical Experiences. Oxford: Young Lives.

Morton, Sarah. 2015. Creating research impact: The roles of research users in interactive research mobilisation. Evidence \& Policy 11: 35-55.

Morton, Sarah, and Jennie Fleming. 2013. Assessing Research Impact: A Case Study of Participatory Research. Research Briefing 66. Edinburgh: Centre for Research on Families and Relationships.

Newell, Sallie, Anne Graham, Robyn Fitzgerald, Zeah Behrend, and Trish Malins. 2012. Child-Led Research: A Pilot of the Today E Tomorrow Research Program. Sydney: UnitingCare Burnside.

Nutley, Sandra, Isabel Walter, and Huw T. O. Davies. 2009. Promoting evidence-based practice, models and mechanisms from cross-sector review. Research on Social Work Practice 19: 552-59. [CrossRef]

Oliver, Michael. 1997. Emancipatory Research: Realistic goal or impossible dream? In Doing Disability Research. Edited by Colin Barnes and Geof Mercer. Leeds: The Disability Press, pp. 15-31.

Petrie, Stephanie, Lisa Fiorelli, and Katie O'Donnell. 2006. 'If We Help You What Will Change?'-Participatory Research with Young People. Journal of Social Welfare and Family Law 28: 31-45. [CrossRef]

Preston-Shoot, Michael, Veronica Wigley, Isabella McMurray, and Helen Connolly. 2008. Reflections on Ethical Research in Action: Working at the Practice Edge. Ethics and Social Welfare 2: 150-71. [CrossRef]

Rayaprol, Apama. 2016. Feminist research: Redefining methodology in the social sciences. Contributions to Indian Sociology 50: 368-88. [CrossRef]

Reed-Danahay, Deborah. 1997. Introduction. In Auto/Ethnography: Rewriting the Self and the Social. Edited by Deborah Reed-Danahay. Oxford: Berg 3PL, pp. 1-20.

Ritchie, Jane. 2009. The applications of Qualitative methods to social research. In Qualitative Research Practice, A Guide for Social Science Students and Researchers. Edited by Jane Ritchie and Jane Lewis. London: SAGE.

Roberts, Amanda, and Judith Nash. 2009. Enabling students to participate in school improvement through a Students as Researchers programme. Improving Schools 12: 174-87. [CrossRef]

Save the Children. 2010. Speaking Out, Being Heard: Experiences of Child Participation and Accountability to Children from Around the World. Available online: https:/ / resourcecentre.savethechildren.net/library/ speaking-out-being-heard-experiences-child-participation-and-accountability-children-around (accessed on 12 November 2016).

Schäfer, Nadine, and Richard Yarwood. 2008. Involving young people as researchers: Uncovering multiple power relations among youths. Children's Geographies 6: 121-35. [CrossRef]

Sharpe, David. 2015. Young people's involvement in policy research. Children's Geographies 13: 240-48. [CrossRef]

Skelton, Tracey. 2008. Research with children and young people: Exploring the tensions between ethics, competence and participation. Children's Geographies 6: 21-36. [CrossRef]

Spalding, Victoria. 2012. We Are Researchers-Child-Led Research: Children's Voice and Educational Value. Manchester: AQA Centre for Education Research and Policy. Available online: https:/ / cerp.aqa.org.uk/sites/default/ files/pdf_upload/CERP-RP-VS-01112011.pdf (accessed on 13 November 2014).

Spyrou, Spyros. 2011. The limits of children's voices: From authenticity to critical reflexive representation. Childhood 18: 151-65. [CrossRef]

Spyrou, Spyros. 2018. Disclosing Childhoods: Research and Knowledge Production for a Critical Childhood Studies. Basingstoke: Palgrave Macmillan.

Thomas, Nigel. 2015. Children and Young People's Participation in Research. In International Perspectives and Empirical Findings on Child Participation: From Social Exclusion to Child-Inclusive Policies. Edited by Tali Gal and Benedetta Faedi Duramy. New York: Oxford University Press. 
Thomson, Pat, and Helen Gunter. 2007. The methodology of students-as-researchers: Valuing and using experience and expertise to develop methods. Discourse: Studies in the Cultural Politics of Education 28: 327-42. [CrossRef]

Tisdall, E. Kay M. 2012. The challenge and challenging of Childhood Studies? Learning from Disability Studies and Research with Disabled Children. Children E Society 26: 181-91.

Tisdall, E. Kay M. 2014. Child Should Be Seen and Heard? Children and Young People's Participation in the UK. In Children and Young People's Participation and Its Transformative Potential. Edited by E. Kay M. Tisdall, Andressa M. Gadda and Udi M. Butler. Basingstoke: Palgrave, pp. 168-88.

Tisdall, E. Kay M. 2015. Children and Young People's Participation: A critical consideration of Article 12. In Routledge International Handbook of Children's Rights Studies. Edited by Wouter Vandenhole, Ellen Desmet, Didier Reynaert and Sara Lembrechts. London: Routledge, pp. 185-200.

Tisdall, E. Kay M. 2016. Conceptualising children and young people's participation: Examining vulnerability, social accountability and co-production. International Journal of Human Rights 21: 59-75.

Tisdall, E. Kay M. 2018. Applying human rights to children's participation in research. In Seen and Heard: An Interdisciplinary Exploration of Researching Children's Participation, Engagement and Voice. Edited by Miriam Twomey and Clare Carroll. Oxford: Peter Lang.

Tisdall, E. Kay M., John M. Davis, and M. Gallagher. 2009. Research with Children and Young People: Research Design, Methods and Analysis. London: Sage.

Törrönen, Maritta Lea, and Riitta Helena Vornanen. 2014. Young People Leaving Care: Participatory Research to Improve Child Welfare Practices and the Rights of Children and Young People. Australian Social Work 67: 135-50. [CrossRef]

Van Blerk, Lorraine, Wayne Shand, and Patrick Shanahan. 2016. Street Children as Researchers: Critical Reflections on a Participatory Methodological Process in the "Growing Up on the Streets" Research Project in Africa. In Springer Handbook of Geographies of Children and Youth. Edited by Louise Holt, Ruth Evans and Tracey Skelton. Singapore: Springer.

Wood, Bronwyn Elisabeth. 2015. Excluded citizens? Participatory research with young people from a 'failing' school community. Children's Geographies 14: 310-24. [CrossRef]

World Vision. 2013. Annual Review: A World Vision for Children, World Vision International. Available online: http:/ / www.wvi.org/international/publication/world-vision-international-annual-review-2013 (accessed on 4 July 2017).

World Vision. 2015. Available online: https://www.wvi.org/sites/default/files/WV-CAY-Led-Research\% 20Methodology-03-11-2016\%20FINAL.pdf (accessed on 4 July 2017).

Wyness, Michael. 2006. Childhood and Society. Basingstoke: Palgrave Macmillan. 